\title{
PURSUIT EYE MOVEMENTS IN GOLDFISH (CARASSIUS AURATUS)
}

\author{
S. S. EASTER, JR. ${ }^{1}$ \\ Department of Physiolony-Anatomy, Univenity of Californic, Barkeley, Culffornit, U.S.A. and \\ Department of Zootosy, University of Michigan, Ann Arbor, Michigan 48104.
}

(Recetioed 14 July; in reoised form 5 October 1971)

\section{INTRODUCTION}

VisuAl cues play an important role in "rheotropism", the tendency of many fish to swim against a current. LYON (1904) found that this motor response could be triggered by movement of visual contours alone, in the absence of currents, and he suggested that the response nulled these movements. As a result, the animal's position relative to stationary landmarks would be maintained in spite of physical forces tending to carry it downstream.

This optomotor response is reproduced in the laboratory by placing a fish inside a striped cylindrical drum which rotates about the vertical axis. There is considerable interspecific variability, but many fish move with the drum, while others reapond only with their eyes, particularly if they are in tactile contact with a non-moving surface such as the bottom of their tank (HARDEN-JONEs, 1963). The whole-body optomotor response has been widely used as a behavional indicator of vision, on the assumption that when the fish can detect the moving field, it responds to it (e.g. GRUNDFEst, 1931; CRONLY-DnLON and MUNTZ, 1965). The ocular response has not been etudied, for none of the investigators of fish eye movements per se dealt with visually-cued eye movements (see EASTER, 1971, for references), and those investigators of the whole-body optomotor response who mentioned eye movoments at all, did so only in pasaing (Srank, 1948; HARDEN-JoNEs, 1963).

Yet it seemed likely that there was potentially interesting information to be gained from a quantitative study of pursuit eye movements, a study in which the magnitude of the response was noted, rather then just its presence or absence. In particular, three features of the goldfish visual system are different from most other vertebrates whose eye movements have been studied.

Firstly, the eyes are situated laterally, with only about $30^{\circ}$ of binocular overlap (Trevarthen, 1968). This is very different from the case in primates with visual overlap of more than $100^{\circ}$. Since the lateral eyes look at very different parts of the world, there is no reason, a priori, to suppose that motion sensed by one eye should influence the movements of the other, but there is no report in the literature dealing with this matter in vertebrates. HoRRmors (1966) has demonstrated a very strong coupling of eye movements in crabs.

Secondly, the goldfish lacks a fovea (HESTER, 1968) and for this reason is thought to have a functionally homogenous retina. But this does not necessarily follow, for ScrwassmanN and KRUGER (1965) found that the receptive fields of tectal afferents (retinal ganglion cells) were considerably amaller in the central retina than in the periphery, and Hesres (1968) showed that the receptor density was also higher centrally. These observations sugeest that

\footnotetext{
1 Preweat address: Department of Zooloy, University of Michipan, Ann Arbor, Michima 48104.
} 
the goldfish might use the central retina as a functionally specialized region, much like the cat's area centralis. If so, the fish should attend to objects of interest by "looking at them"; that is, by directing its eyes so that the objects are imaged on this area, and a record of eye position should reveal such attention.

Thirdly, the goldfish lacks a cerebral cortex (ARIENS-KApPERS, HuBER and CrosBY, 1967). The most extensive comparative study made on vertebrate eye movements was restricted to mammals, all of which normally have a cortex (TER BRAAK, 1936).

Finally, a more general reason for undertaking this study lay in the hope that the sensory-motor integration could be easily analyzed. The stimulus, a moving target, can be altered in a variety of specified ways. The response, eye movement, can be measured accurately and simply. The intervening nervous system, lacking a cortex, is physically quite small and therefore amenable to detailed physiological analysis. This report deals with the relation of stimulus and response; the organization of the intervening nervous system will be taken up in future reports.

\section{METHODS}

The mothod of measuring eye position has been deccribed in detedl olpowhere (Bustma, 1971). Briefty, an unanesthetizod goldfish (12-18 cm lons) was raturained, in a watenalled tranepereat phatic cylinder, circular in horizontal cross section. A rigid stalk was attached by ruction to each cornes, above the Hae of sight, as shown in Fig. 1. As the eye moved, so did the stalk. A flying epot scanner amplod the orientation of each stalk in the horizontal plane many times per second, and the data appoured on either a stornge

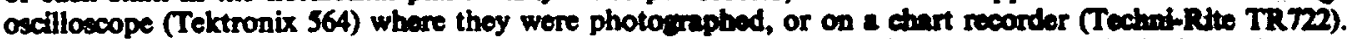
Upward and downward defiections on the records correapond, roapectivaly, to counterclookwios and ctockwise movements of the eyes as seen from above. Whenever the records of both eyes are shown, the left is above, the right below.

Moving tarpts were presented either on a rotating drum concentric with the animal's head, or on tancont screens; in both cases, the tarret was out of water. The drum subtendw $100^{\circ}$ of the animal's visural feld in the vertical plane and $280^{\circ}$ horizontally. Its inner surface was lined with elternating black and white stripes of $7^{\circ}$ subtense, and rotated about the vertical axis. The drum position wim monitored by a conductive plastic circular potontiomoter, the shaft of which was the axle for a amall friation wheel resting on the top of the drum. As the drum rotated, it drove the friction wheel, and the potentiometer voltape varied linearly with drum angle, although one turn of the drum caused many turns of the friction whool. The voltare out was differentinted electronically, to give a signal which calibration proved was linear with drum angular volocity. Figure 3, for example, shows two records of drum velocity; upwand and downward detiections correapond to counterclockwise and clockwise rotations respectively. The periodic splke-like excurrions from the maintained levels are electrical artifacts resultins from the $10^{\circ}$ dead space in the potentiomoter. The tancent screens were two kymograph-driven belts, $25 \mathrm{~cm}$ high and $1 \mathrm{~m}$ lons, with stripes similiar to thoce on the drum. The belts were placed on oither side of the animal, $15 \mathrm{~cm}$ from the corneas, and moved indapendently.

Pursuit velocities were obtained from oscillographs of eye position by measuring the slopes of the pursuit movements at no fewer than five preselected places in the photograph. Most commonly, the slopes were measured at $0.1,0.3,0.5,0.7$, and 0.9 of the full horizontal sweep, which varied from 5 sec for high velocities to $50 \mathrm{sec}$ for the slow ones.

Most fish were used in only one sossion, which usually lasted loas then 2 hr. Each exparimant was labelled "FEM-" followed by some number. The early experiments (FEM-1 to FBM-56) were carriod out in Berkeley, the later ones in Ann Arbor, and the experimental equipment dinfored allihtly in the two place. In Burkeley, the drum dia. was $46 \mathrm{~cm}$. the sampling rate of the tyins epot scanner was $36 / 60 \mathrm{c}$, and the ratio of reflectances

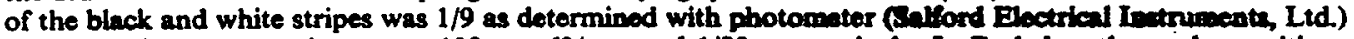
In Ann Arbor, the numbers were $102 \mathrm{~cm}, 60 / \mathrm{sec}$, and 1/20, roupectively. In Bexteloy, the coular positions

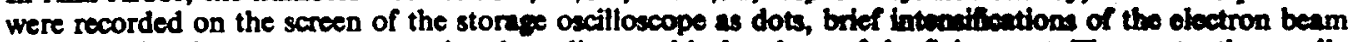
whose vertical input was a sawtooth voltuge linear with the phane of the flyins apot. The samtooth, wanally invisible, was intencifiod only when an eye stalk intercepted the tyytng spot. This method was lintived in its usefulness by the fact that the data were available only from the oscillowingha, and not as olectrical signals. In Ann Arbor, this limitation was overcome by employing a samplenad hold ctrcuit (Burr-Brown Model 4013-1/25) which sampled the value of the sawtooth whoover the attilk and epot met, and bold this value until commandod to sample again. Separate sample-and-hold units were uned for the two eyes, reulting in a pair of analog eloctrical voltages, each simalling the most recently sampled position of one eye. 


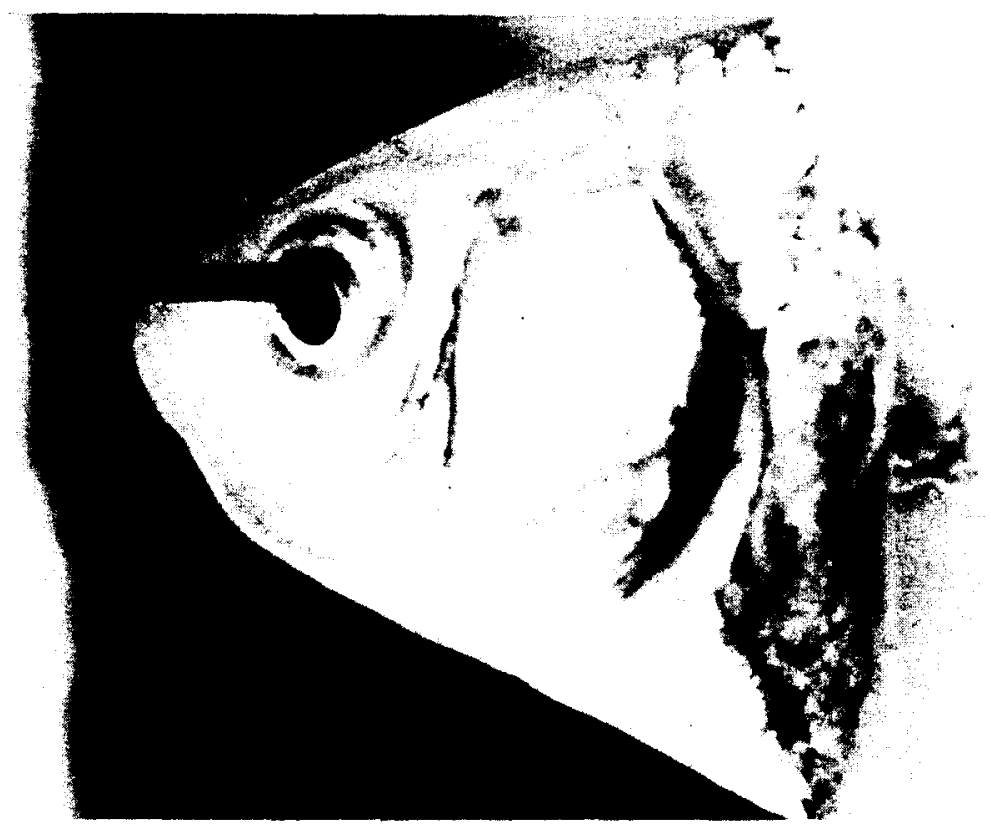

FIG. 1. This is a lateral view of a goldfish, restrained in a sponge-lined holder, with the opaque polyethylene stalk attached by suction to the cornea. The length of the stalk is $1.2 \mathrm{~cm}$. 

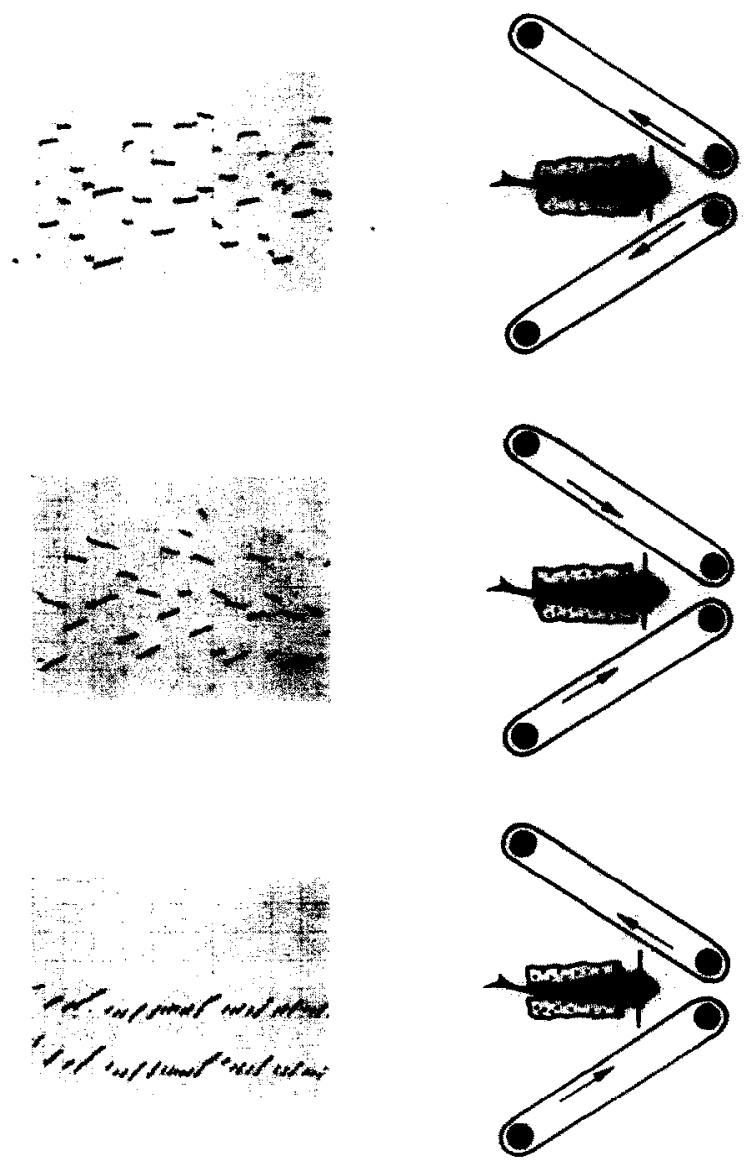

FIG. 8. Tangent screen experiments (FEM-19). The sketches at the right schematize the experimental conditions which evoked the responses at the left. In all cases, the tangent screens were lined with alternate black and white stripes and moved at $20^{\circ} / \mathrm{sec}$. Calibration: $15 \cdot 3^{\circ} /$ large division vertically, $5 \mathrm{sec} / \mathrm{large}$ division horizontally. 


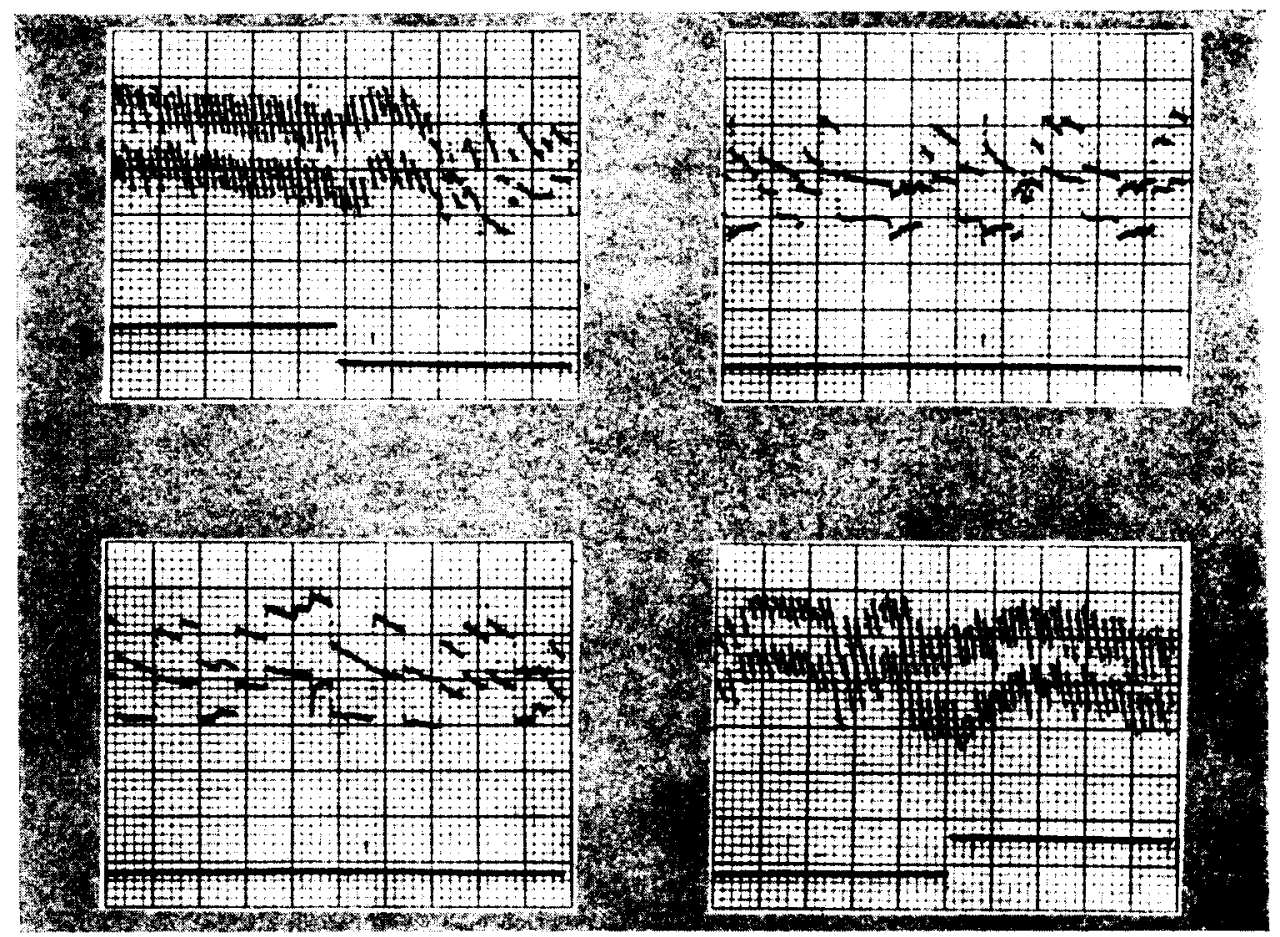

FIG. 11. Adaptation and OKN. (FEM-33) In all four oscillographs, the upper two traces give the eyes' positions, the lowest gives the output of a photocell monitoring the general illumination. In all, the drum rotated at $30^{\circ} / \mathrm{sec}$. Top left: The lights dimmed, and $\mathrm{OKN}$ ceased. Top right followed by lower left: These two were taken in that order, minutes apart; the tracking speed gradually increased as the animal adapted to the dark. Lower right: Finally, after about 5 min of dark adaptation, standard $O K N$ was resumed in the dim light. When the lights went on again, OKN continued. Calibration: $23.0^{\circ} /$ large division vertically, $5 \mathrm{sec} /$ large division horizontally. 


\section{RESULTS}

\section{Qualitative aspects of pursuit}

In the presence of a stationary visual field, the restrained goldfish spontaneously flicked its eyes from side to side, as may be seen in Fig. 2, upper row. During the intersaccadic intervals, the eyes drifted nasally with a velocity of about $0.5^{\circ} / \mathrm{sec}$ (EASTER, 1971). (With the convention used here, nasad rotations are downward in the upper trace, upward in the lower.) When the drum rotated slowly, at less than about $3^{\circ} / \mathrm{sec}$, the spontaneous saccades continued with much the same rhythm as before, but during the intersaccadic intervals, a new drift in the direction of the drum's rotation was superimposed on the spontaneous nasad drift already present. For example, clockwise movement of the drum would be expected to induce nasad movements by the left eye, temporad motion by the right. When, as in Fig. 2 (second row, right column), the drum moved clockwise at $1.6 \%$ sec, the nasad drifts by the left eye increased, while those of the right eye were essentially abolished. For larger target speeds, the spontaneous saccades ceased, and the animal showed standard

\section{$F \mathbf{M}-101$}

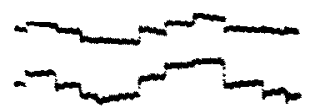

-

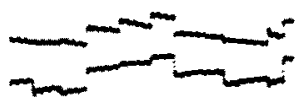

$1+6$
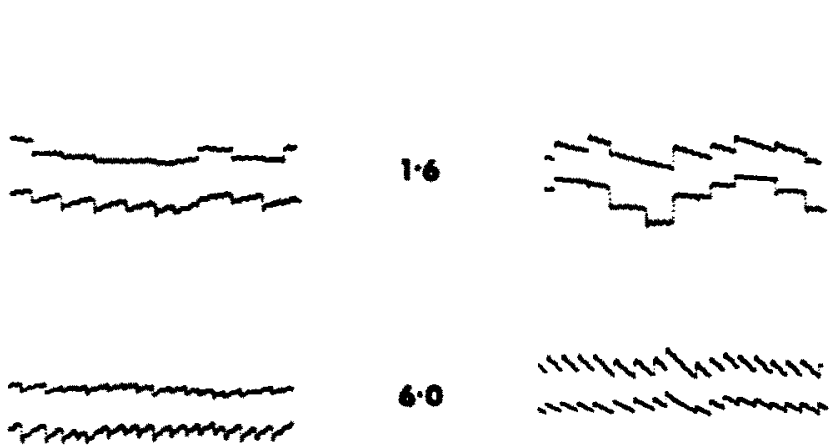

$6 \cdot 0$

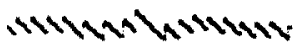

premparmenerep

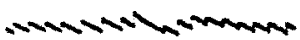

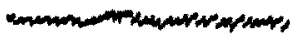

Fig. 2. These are representative samples of eye movements, by one animal, in response to a striped drum rotating in counterclockwise (CCW) and clockwise (CW) directions at the angular velocities (degrees/second) given by the numbers in the central column. The animal viewed the drum over its full extent, $100^{\circ}$ in the vertical plane, $280^{\circ}$ in the horizontal. The luminance of the dark and light stripes were $-0-5$ and $0-8 \log \mathrm{f}-\mathrm{L}$, respectively. Conventions: left eyo abovo, right eye below; clockwise downward, counterclockwise upward. Calibration: $30^{\circ}$ vertically, $10 \mathrm{sec}$ horizontally. 
optokinetic nystagmus (OKN), in which nearly every pursuit movement was followed by a reset saccade in the opposite direction (Fig. 2, third and fourth rows from the top). It should be noted that the nasally directed pursuit velocity was still generally the larger, even for a target velocity of $15 \% \mathrm{sec}$. The asymmetry shown in this figure is more pronounced than usual, but it was generally true that the tracking responses were not perfectly equal in both eyes, even when both saw the same drum velocity, as here.

The saccadic response to movement was surprising. An abrupt step-like rotation of the drum failed to trigger a matching saccade, as occurs in humans (WESTHEIMER, 1954). Instead, the fish either failed to respond at all or else made a saccade in the opposite direction. A saccade directed against the movement could also be evoked by slow or moderate rotations of the drum, as Fig. 3 illustrates. In both records, the trace begins with the drum

\section{$P B M-102$}
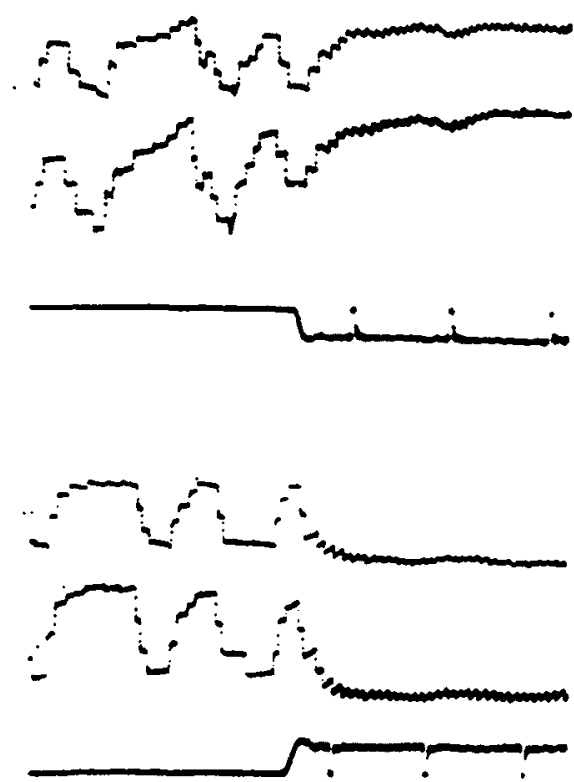

F10. 3. OKN and coular positions. In both sets of three trecos, the drum was initinlly motion-

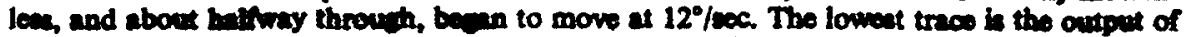
a drum velocity moter. Above: the drum rotated clockwibe, and the eyse sulined to extreme counterclockwise positions. Below: the drum rotated counterclockwise, and the oyes moved to clockwise positions.

motionleas, and the eyes moving spontaneously from side to side over $30-40^{\circ}$. Then, about halfway through each record, the drum began to move, clockwise above, counterclockwice below, and the oyes quickly respondod with seccades in the opposite dircuions. During the intertacendic intervals, the smooth purnuit movemonts carried the oyen in the direction of the drum, but, within a few sec, the saccades had prevailed, and the eyes were relatively restrictod to a now operatias point, chifled away from the midline towand the oriain of the movement. The range of positions is much smaller during OKN than during the epontaneous 
mode, and its position relative to the midline is interesting, in view of the common supposition (e.g. WarLs, 1962) that during OKN the eyes pursue until they can go no farther, and then reset. This is clearly untenable, since the fish reset long before reaching an extreme position, and in fact reset from a relatively intermediate position to an extreme one.

This observation that the direction of the stimulus movement set the positions of the eyes was investigated further to ascertain if the position of the stimulus played any role in setting the ocular positions. This was prompted by the guess that if the retina contained some region specialized for acute vision, then the animal might make some effort to direct it toward the moving part of the field, as mentioned in the Introduction. Inasmuch as most of the animal's field was filled by the moving drum, it was necessary to localize the movement, and to this end, opaque black felt cloths were draped over the chamber, leaving only a single window subtending $45^{\circ}$ horizontally and $100^{\circ}$ vertically. (When the cloth covered the entire tank, the fish did not respond to movement of the drum, proving that the cloth was in fact opaque.) The window was positioned in either the nasal, central, or temporal region of the left visual field; that is, centered at $45^{\circ}, 80^{\circ}$, or $115^{\circ}$, with the anterior direction taken as zero degrees. The results from one animal are seen in Fig. 4, a dozen scatter diagrams obtained by connecting the outputs of the two sample-and-hold units to the

\section{FEM-81}

STIL
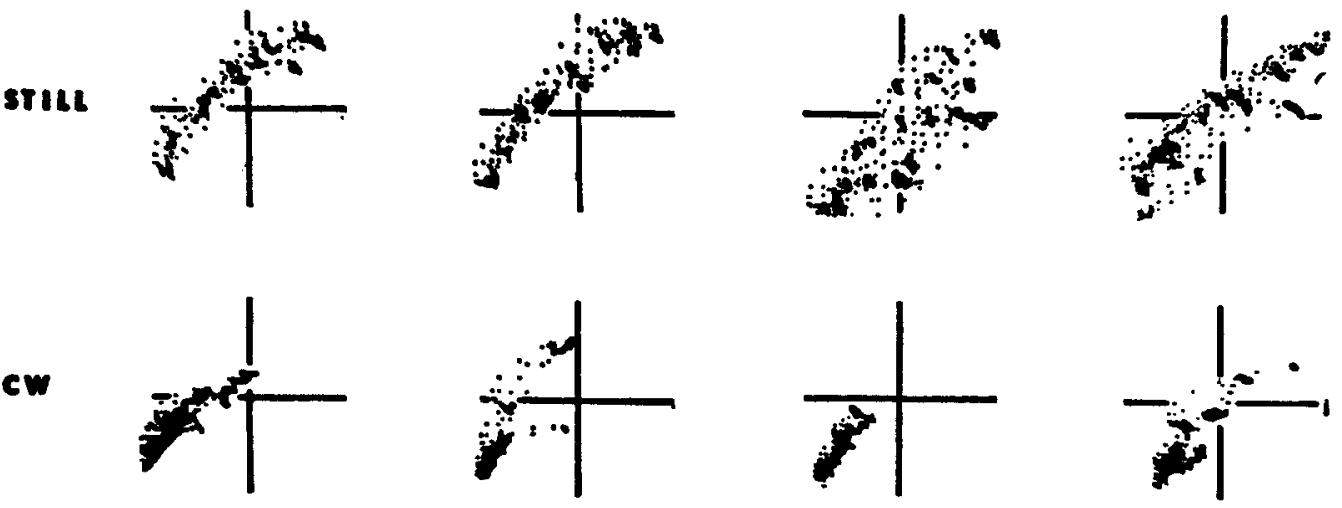

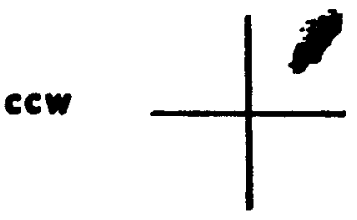

1F $\$ 28-149$

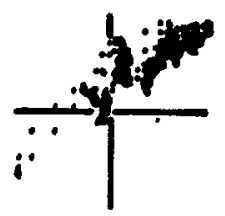

NLF123-68

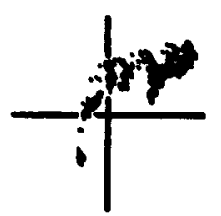

CLF:68-112

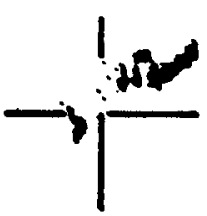

TLF:95-140

FIG. 4. Target position and ocular positions. These are scatter diagrams in which the left eye's position is plotted vertically, the right eye horizontally, with clockwise movement to the right and upward. The axes subtend $35^{\circ}$ each. and intersect at the midpoint of the extreme positions assumed by the eyes in this experiment. The legends to the fert moicate the state of the drum: still, rotating clockwise or counterclockwise at $12 \% \mathrm{sec}$. The legends below indicate the field of view for the data in each column: LF, Ieft field; NLF, CLF, TLF, nasal, central and temporal left field. The numbers indicate the angular position of the field of view in the horizontal plane, relative to $0^{\circ}$, the anterior direction. 
storage oscilloscope. The left eye appeared on the vertical axis, the right, on the horizontal. The clockwise direction is along the $45^{\circ}$ line; that is, upward (left eye) and toward the right (right eye). As the eyes moved, the beam discontinuously indicated the most recently sampled positions of each. Since left and right eye samples were obtained at approximately $8 \mathrm{msec}$ intervals, the beam jerked around the screen in steps separated by this period. First, say, it moved upward indicating that the left eye had shifted clockwise since last sampled. Then, about $8 \mathrm{msec}$ later, it moved to the right, indicating a clockwise shift by the right eye. Thus the beam stayed at each position for $8 \mathrm{msec}$, and this was sufficiently long to leave a stored image of the nearly simultaneous positions of the eyes. During the beam's quick shifts, it left no trace. In the scatter diagrams, most single dots represent interim positions during a saccade, while the presence of a broader blackened area indicates that the eyes spent a relatively long time there, either drifting or tracking between saccades. Each of the oscillographs represents one minute's movements, and each was obtained under different conditions. The rows have in common the drum movement: still, clockwise at $12 \%$ $\mathrm{sec}$, or counterclockwise at the same speed. The three oscillographs in each column were obtained with identical fields of view, as indicated below each. In the upper row, the drum was stationary, and the eyes flicked back and forth over the normal range of $30-40^{\circ}$, regardless of the position of the window. When the drum moved, the eyes responded with a sluggish but unmistakable OKN despite the restricted view of the target, and the second and third rows show that the range of positions assumed did not depend on the window. In the second row, where the drum moved clockwise, the eyes shifted toward the lower left quadrant, corresponding to the left and right eyes assuming temporal and nasal positions, respectively. This shift in position was the same no matter where the window appeared. Similarly, when the drum moved counterclockwise, the eyes shifted toward a clockwise set of positions. These data do not support the hypothesis of a specialized retinal region; they favor the notion that the goldfish retina is functionally homogeneous.

Onset of drum rotation evoked pursuit within a fraction of a second, as Fig. 3 showed, but the response initially was rather slow and gradually, over seconds, built up to a steady, high velocity. Figure 5 illustrates the results of an experiment investigating the behavior when the drum stopped rotating. The upper trace (PC) is the output of a photocell monitor-

\section{FEM-103}
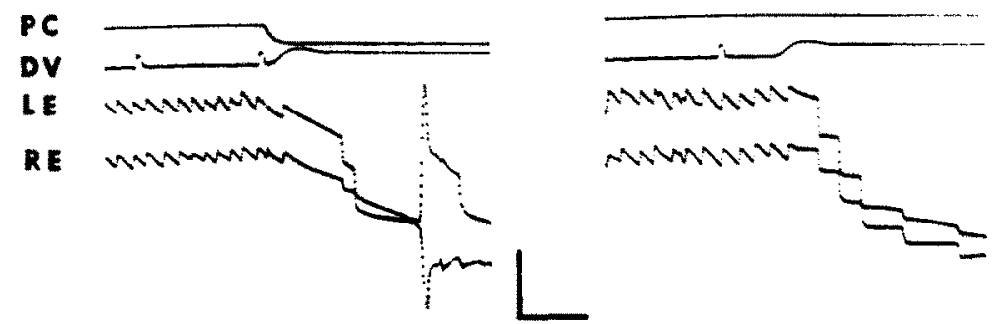

Fig. 5. Optokinetic afternyatermul PC: this trace gives the output of a photocell indicating light intensity inside the drum. Inithlly it is bith in both cases; balfway through the recond on the left it is abruptly decreaned to a lovel at which the drum is no lonvar diecernible. DV: this gives the drum volocity, initially $12 \% / 20$, theo $0^{\circ} / 20 c$ about halfway thrount ench trace. LE, RE: the left and right eyes. Calibration: $30^{\circ}$ vertically (eye position), 1 sec horizontally. 
ing ambient light level; downward deflection indicates a decrease. The second trace is the drum velocity, initially $12 \% \mathrm{sec}$ clockwise, and later zero. The lower two traces give the eye positions. The record on the right shows that when the drum stopped and remained visible, the eyes responded abruptly, with a rapid deceleration, quite unlike the gradual acceleration with onset of drum rotation. However, when the room lights were extinguished simultaneously, as they were in the record on the left, then the eyes continued "pursuit" in the dark for several seconds. They did so if the drum continued to rotate or even reversed direction, and then reverted to the spontaneous mode, indicating that the decrease in light level had rendered the drum imperceptible. This prolongation of the response is called optokinetic afternystagmus (OKAN), and it has been observed before by TER BRAAK (1936) in mammals. They showed OKAN even when the field remained visible, unlike the goldfish. More recently, WIEGMANN (1958) has investigated the phenomenon in man under much the same conditions as used here, with similar results.

\section{FEM-46}
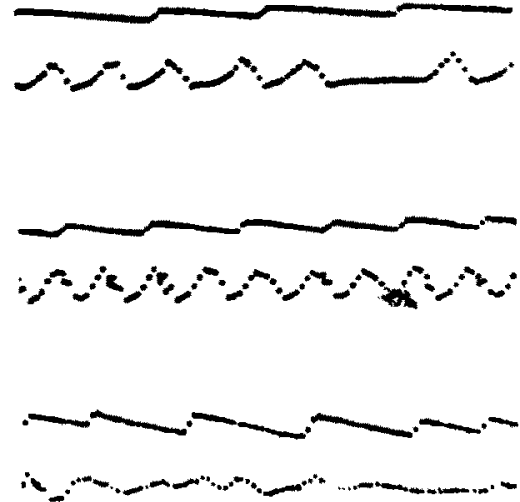

Fig. 6. OKN and the optomotor response. In each of the throe pairs of traces, the upper is the right eye, the lower, the right pectoral fin. The numbers to the right give the drum velocity in degrees/second. Calibration: $40^{\circ}$ vertically (cye position), $0.5 \mathrm{sec}$ horizontally.

An indicator of the whole-body optomotor response could be observed when one of the pectoral fins was not clamped along with the body. When this was done, the fin was free to stroke as it would if the animal were unrestrained, and its position was sensed by the flying spot. The lower trace in each of the three pairs in Fig. 6 shows the right pectoral fin's movement, the upper trace, the right eye. This figure illustrates that the phases of the two responses-fin stroke and eye movement-were not related, but seemed to be independent events. Moreover, the fin stroke was a much more erratic response than OKN; so is the whole-body response as observed in freely-swimming goldfish. 


\section{Quantitative aspects of pursuit}

In this subsection, a number of factors were varied and their quantiative effects on the pursuit velocity noted.

Target velocity. The frequency, amplitude, and velocity of pursuit movements increased with drum velocity up to some maximum value, usually in excess of $40 \% \mathrm{sec}$ (drum velocity) and then levelled off or decreased. The quantitative relation between drum and ocular velocities was investigated in a series of identical experiments on four fish (FEM-118-121). Each was restrained as usual, and viewed the drum binocularly over $280^{\circ}$ horizontally, $100^{\circ}$ vertically. The inside of the drum was illuminated by flood lights, several meters distant, resulting in the white stripes having a brightness $1.9-2 \cdot 1 \log \mathrm{ft}-\mathrm{L}$, the black stripes, $0.6-0.8$. The animal was allowed about $10 \mathrm{~min}$ to adapt to the relatively high light level, and then was exposed to two ascending velocity series, one each in the clockwise and counterclockwise directions. Two animals experienced the series in clockwise-counterclockwise order,

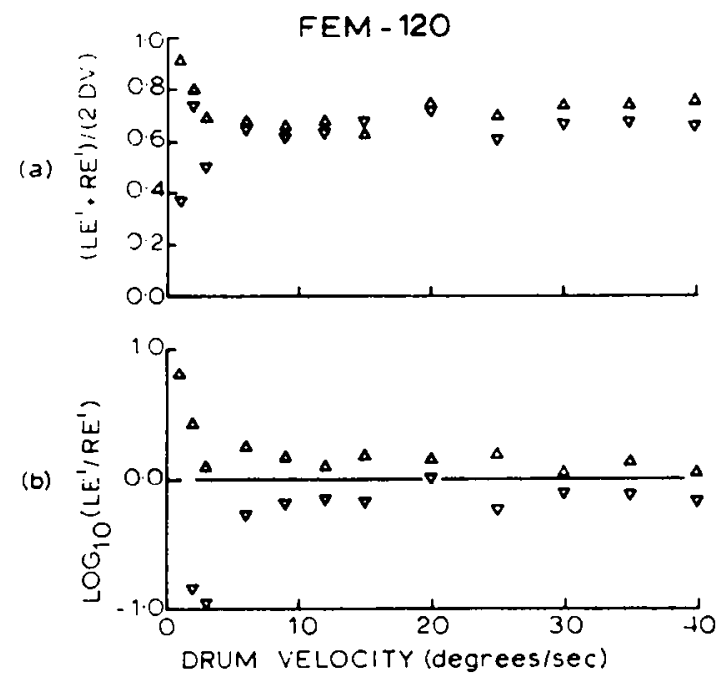

F10. 7. Punuit velocity and drum velocity. (a) The ordinate gives the averape valocity enin of the two eyes vs. the drum velocity (drapres/meond). (b) The ordinate sives the losurithm of the ratio (hit eye valocity/titht eye velocity) vs. the drum velocity. The inverted triande at $1 \% / 0 e c$ is omitred in (b) becanes at this low speed, the eyes moved in opponite directions, owing to the

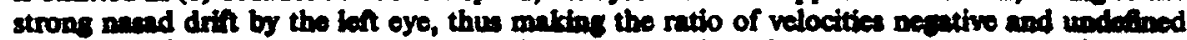

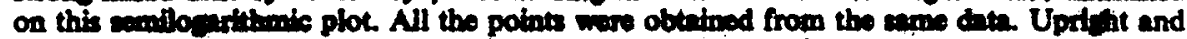
inverted trandes rofer to clockwibe and counterclockwibe rotations, reipectively.

two in the reverce. First, a record was obtained of the animal's eye movements with a motionless drum, then the velocity was set at $1.0 \% / \mathrm{sec}$, and at least $30 \mathrm{sec}$ eirpead before an oscillograph was made. Preliminary expariments showed that this 30 soc dolay allowed the animal to stabilize at its maximum response. The velocity was then incremented, and the process repeated, until two ascending series were completed. Velocities were: $0 \cdot 0,1 \cdot 0,2 \cdot 0$, $3 \cdot 0,6 \cdot 0,9 \cdot 0,12,15,20,25,30,35$, and $40^{\circ} /$ sec. Earlier experiments had shown that the response to a given velocity was often smaller during a descending series than in an asconding one, so the former were not used. 
Figure 7a gives the velocity gain (pursuit velocity/drum velocity) for one animal, as a function of the drum velocity. The other fish gave qualitatively similar plots, although their gains differed. It should be noted that the pursuit velocity used is the mean value of both eyes. This is preferable to either alone, because errors in centering the animal in the circle of light traced out by the flying spot cause equal movements by the two eyes to be recorded unequally (EASTER, 1971), one larger than the true value, the other smaller. Their mean gives the true mean value.

The gain was always less than unity; that is, the eyes never matched the velocity of the drum. The mean gain was 0.68 , but differed significantly depending on which direction the drum rotated. In all cases but one $\left(15^{\circ} / \mathrm{sec}\right)$, gain for clockwise rotation was the greater. The mean clockwise gain, averaged over all twelve velocities, was $0 \cdot 73$, while the mean counterclockwise gain was 0.63 . These differences are only barely significant statistically, but in the other animals, the imbalance was much gi eater, and very significant. For instance, FEM-119 had a mean clockwise gain of 0.87, while the value for the other direction was only $\mathbf{0 . 4 4}$. This unexpected asymmetry suggests an instrumental artifact of some kind, but a reexamination of other records obtained on the same instrument under identical conditions revealed that other fish showed a pronounced counterclockwise bias, while still others were essentially equal in the two directions. Thus the effect seems to be a real one.

Figure $7 \mathrm{~b}$ was obtained from the same experiment as Fig. $7 \mathrm{a}$, and the data are plotted to illustrate quantitatively the point made qualitatively from the records of Fig. 2; namely, that nasad rotation exceeded temporad. The ordinate gives the $\log$ of the ratio (left eye velocity/right eye velocity). The horizontal line shows, for reference, unity ratio. The upright triangles were obtained for clockwise rotation, which causes nasad movement by the left eye, temporad by the right. All are above this line, indicating that the left eye's velocity was larger for all clockwise stimuli. The reverse was true for counterclockwise rotations-all the inverted triangles are below the horizontal. It seemed possible that this nasad bias was due solely to the resting drift in each eye, and if each eye's pursuit velocity were corrected to represent the difference from this resting drift, rather than from zero, then the pursuit movements might be conjugate. Such was not the case, however. When these corrections were made, the nasad response still exceeded the temporad.

Binocular and monocular viewing. It is of some interest to learn how a target seen by one eye affects the movements of the other, and these interocular relations were assessed by measuring the pursuit velocities of each eye when both or either alone viewed the drum.

First the anterior $45^{\circ}$ (in the horizontal plane) were shielded by black cloth. This more than covered the region of binocular overlap (TREVARTHEN, 1968) and gave each eye an independent view of the drum. Either or both of these views could then be shielded by a second black cloth. The drum rotated at $3^{\circ}, 6^{\circ}$, or $9^{\circ} / \mathrm{sec}$, clockwise or counterclockwise, and the movements of both eyes were monitored when both, or the left alone, or the right alone, viewed the drum. Then the mean velocity of each eye was determined for each drum velocity, and the values compared. The comparison was made by computing two ratios:

$$
E^{\prime}{ }^{\prime} / E_{b v}^{\prime} \text { and } E_{c v}^{\prime} / E_{b v}^{\prime}
$$

where:

$E_{b v}^{\prime}=$ the response by one eye when both eyes viewed the drum (binocular view), $E_{i p}^{\prime}=$ the response by one eye when it alone viewed the drum (ipsilateral view), 
and

$E^{\prime}{ }_{c v}=$ the response by one eye when only the other viewed the drum (contralateral view). This same experiment and analysis were carried out on three fish, with similar results for all. They were pooled, and are summarized as follows (means \pm S.E.M.):
$\left(E^{\prime}{ }_{\text {lv }} / E^{\prime}{ }_{b v}\right)=0.65 \pm 0.03$,
$(N=18)$
$\left(E_{c v}^{\prime} / E_{b v}^{\prime}\right)=0.44 \pm 0.03$.
$(N=18)$.

They indicate that an eye's response was largest when both viewed the target, next largest if the eye itself viewed it alone, and smallest if only the contralateral eye did so. The 5 per cent confidence limits for the two ratios are set by the means \pm two S.E.M. which makes:

$$
\begin{aligned}
& \left(E^{\prime}{ }_{i v} / E_{b 0}^{\prime}\right)=0.59-0.71 \\
& \left(E_{c o}^{\prime} / E_{b v}^{\prime}\right)=0.38-0.50 .
\end{aligned}
$$

The ranges of uncertainty are large enough to support the hypothesis that the response to a binocular view was the linear sum of the responses to the two monocular views. This is undoubtedly an oversimplification, but it is quite surprising to find that the results even approximate this linear addition.

Another approach to the interdependence of the eyes is to present them with stimuli expected to evoke non-conjugate pursuit. This was done using tangent screens, as schematized in Fig. 8. The sketches on the right show the experimental situation as viewed from above; in all cases, the screen velocity was $20 \% \mathrm{sec}$ at the point nearest the cornea. The bottom record, in which the right screen moved nasally and the left one caudally, corresponds to counterclockwise movement of the drum, and the animal responded with ordinary OKN. In the middle record, both screens moved nasally, and each eye responded appropriately to the ipsilateral screen, although with a slower speed than in the lowest record. Apparently the stimulus to the contralateral eye slowed the response to ipsilateral stimulation. In any case, the response was not OKN, for the saccades were sometimes in the direction of the slow phase, sometimes opposed. Simultaneous saccades were usually in the same direction as one another, and unequal in magnitude. The temporally-directed one was systematically the larger, thus making the saccades divergent. This same use of disconjugate saccades to stabilize vergence (the interocular angle) was noted before in spontaneous movements (EASTER, 1971). Finally, the top record shows that when both screens moved caudally, the animal ignored them both; the activity is indistinguishable from what was observed in a stationary field or darkness.

Window size. Black opaque masks were positioned outside the animal's container and placed to provide a window through which it viewed the drum. The angular subtense of this window could be varied in both the horizontal and vertical dimensions. The drum rotated at a constant speed and the size of the window varied. When the vertical subtense was fixed at the maximum $\left(100^{\circ}\right)$ and the horizontal subtense changed from 0 to $280^{\circ}$, the animal responded with a tracking speed that increased monotonically with the horizontal subtense; these data appear in Fig. 9a. Similarly, when the horizontal subtense was fixed and the vertical varied, the same sort of spatial integration was observed (Fig. 9b). Apparently, the velocity of the tracking response depended not only on the velocity of the target, but on its size as well, and no threshold size could be discerned.

Contrast. In all the experiments described thusfar, the entire drum was lined with stripes of the same contrast ratio. In order to assess the effect of contrast, the dark stripes on one 


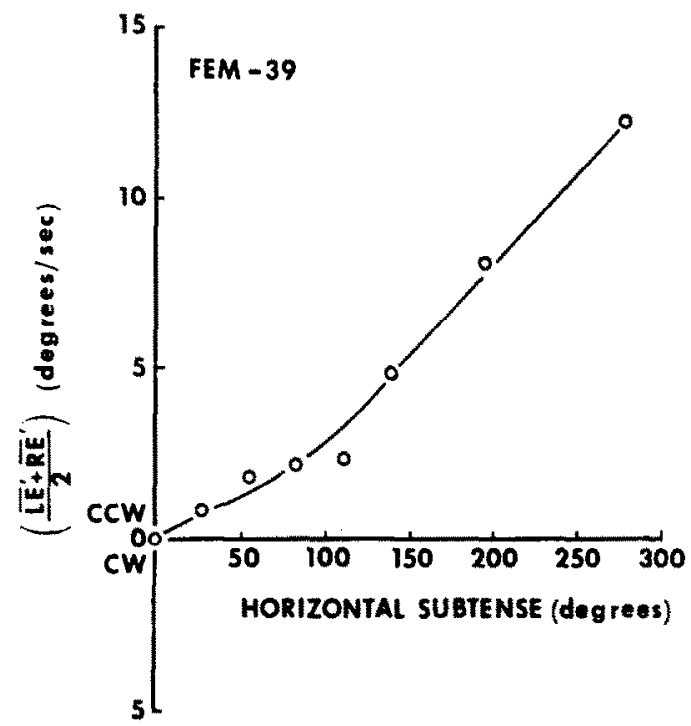

(a)

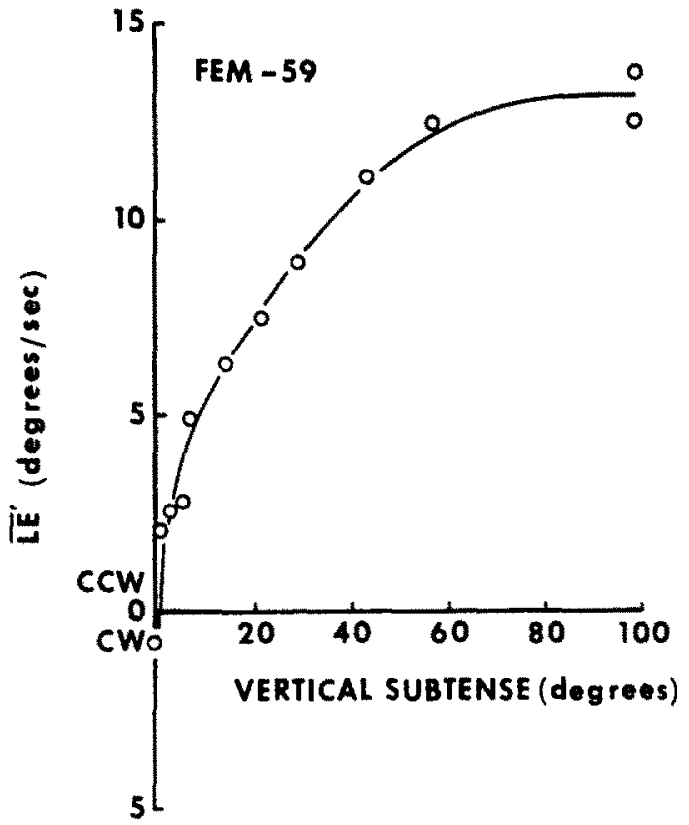

(b)

Fig. 9. Tareet size and pursuit velocity. In both cases, the drum rotated at a constant $15^{\circ} / \mathrm{sec}$ counterclockwise and the fish viewed it through windows of variable subtense. (a) Both eyes viewed the drum through a window subtending $100^{\circ}$ vertically, and a variable amount (abscissa) horizontally. The window was centered anteriorly and increased symmetrically to either side. The ordinate gives the mean response of both eyes. (b) Both eyes viewed the drum through a window subtending 280 dogrees horizontally and a variable amount (absciasa) vertically. The window was centered at eye level and increased symmetrically above and below. The ordinate gives the mean response of the left eye. 


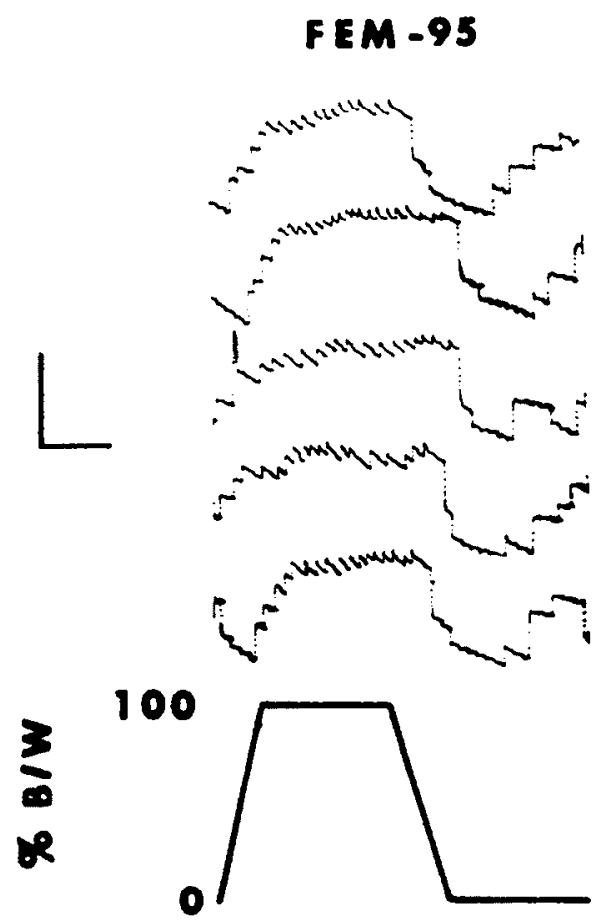

Fro. 10. Contrast and OKN. The upper five traces are all by the left eye, diepinced vertionlly for clarity. Bech swoep cocupied the time required for one revalution of the drum, one hall of which was covered by blect and white stripes (rellectance ratio: 1:20) the other half with eray and white atripes (refloctance ratio: 12:20). The animal viowed the drum ooly through a window of $60^{\circ}$ horizontal subtense in the len field. The loweat trace indication on tho same time basin, the percentale of this view ocaupied by black/white, as opponed to ersy/whitte, stripes. See text for further details. Culibration: $30^{\circ}$ vertically (eye position), 10 sec borteontally.

half of the drum were replaced with lighter ones, leaving this half with relatively low contrast. Once again, the fish's container was shielded over most of its surface, with only a window subtending $60^{\circ}$ horizontally, $100^{\circ}$ vertically, in the left central field. When the drum moved, the right eye saw only the uniform black cloth, while the left eye saw a moving striped pattern which was at first (say) all low contrast, with the high contrast portion just coming into view. For $1 / 6$ revolution, the high contrast field gradually supplanted the low, until it occupied the entire $60^{\circ}$ window. Then, for $1 / 3$ revolution, the view was entirely high contrast, until it too was supplanted by the low over $1 / 6$ turn. Then the cycle was completed, as the fish viewed exclusively low contrast over the final $1 / 3$ turn. It was noted independently when the field changed, and the pursuit behavior was observed for a number of revolutions at various speeds. Some of the results of one experiment are given in Fig. 10, which shows five successive traces by the left eye. Clearly, when the high contrast fiald was in view (indicated below) the roeponse was a vigorous OKN. As the low contrant took over, the tracking epead diminished, and the eyes wandered from their relatively reatrictad positions. When different drum velocities were used, the cyclic bohavior seen in Fig. 10 was always phaso-locked with the drum. A varioty of contracts, all greater then the golelech's threehold (HESTER, 1968), were used, and the tracking velocity increased monotonically with contrast. 
In a related experiment, the number of uniformly dark stripes on the drum was varied, and as they decreased, so did the pursuit response, in a graded fashion.

Ambient light intensity and adaptation. An experiment illustrating the effects of light level is shown in Fig. 11. The top two traces in each oscillograph are the left and right eyes. The lowermost trace is the output of a photocell monitoring the ambient illumination of the experimental chamber. As the experiment began, in the top left oscillograph, the drum was moving at $30^{\circ} / \mathrm{sec}$ clockwise, and the animal was responding. About half way into this picture, the ambient intensity was reduced to that provided by scatter of the flying spot by the water. Although the drum continued to move, the tracking speed gradually slowed down (OKAN). A few moments later, when the top right oscillograph was made, the eyes were no longer tracking, presumably because the drum was no longer perceptible. As dark adaptation proceeded (bottom left), the eyes gradually began to track; note the occurrence of many downward sloping intersaccadic intervals in both eyes. Finally, when dark adaptation was complete, the eyes were tracking at about the same speed as in the light (bottom right). When the light was turned on again, OKN continued unabated.

This gradual increase of tracking velocity probably reflected the increasing apparent contrast of the target. As the animal dark adapted, the stripes became more pronounced, and therefore constituted a more powerful stimulus, despite the fact that their velocity was constant.

\section{DISCUSSION}

Probably the most surprising part of the results is the wide range of factors which influenced the pursuit velocity. Since these eye movements are usually considered to stabilize the retinal image, it would be expected that once a moving target was detected, it would be tracked with an ocular velocity dependent only on that of the target. But this was not the case. To be sure, it did depend on target velocity, but only partially. Figure $9 \mathrm{~b}$ shows that when the movement was observed through a ribbon-shaped window subtending only two degrees in the vertical plane, the eye clearly responded, but its speed, $2 \%$ sec, was much smaller than the target itself. As the window grew, so did the response, indicating that the pursuit velocity was computed from a spatial summation of movement sensed over a large part of the retina. This suggests that the retina is indeed functionally homogeneous, that a large velocity in a small area has the same behavioral result as a smaller velocity in a larger area. The other two factors which influenced pursuit velocity, contrast and state of adaptation, can be construed as making the target movement more noticeable, and tending to make the eyes approach a velocity which is limited by, but not equal to, the velocity of the target.

The animals showed directional selectivity, in that movement of the target from posterior to anterior was generally a more effective stimulus than movement in the opposite direction. It is quite clear in Fig. 2, Fig. 7b and Fig. 8, and this same preference is evident in a variety of species when the optomotor response is observed (TAUBER and ATKIN, 1968). There are two ways to interpret this. One is the naturalist's approach, to recognize that the animal spends all its life swimming forward through the water, so that its visual field is always moving backward. This direction of movement is usual, and therefore uninformative, whereas movement in the opposite direction is rare and for that reason alone warrants attention.

A plausible physiological interpretation is in terms of directionally selective movement 
detectors in the retina. Cronly-Dillon (1964) first described these units in the goldfish, and he noted that most units sensitive to movement in the horizontal plane had a preferred direction in the visual field from rear to front. If the pursuit movements were governed by a neural center responsive to the number of directionally selective units firing, then large areas would be more effective than small ones, and the anterior direction would be the more effective, as observed. WARTzOK (1971) has confirmed and extended Cronly-Dillon's results to investigate the relation between the stimulus velocity and the response of these units. He found that they are sensitive to velocities between about 1 and $12 \%$ sec, and both of these limits compare favorably with the pursuit eye movements. As noted above, the restrained fish's eyes drift nasally at something less than $1 \% \mathrm{sec}$, even when there is no movement in the field. This spontaneous drift results in a drift of the retinal image, and the fact that the animal fails to stabilize the eye suggests that its velocity sensors do not respond to drifts of this speed. The upper limit found by Wartzok is compatible with the finding that the velocity gain was approximately constant up to drum velocities of $40^{\circ} / \mathrm{sec}$. A typical velocity gain was 0.7 ; this means that when the drum rotated at $40^{\circ} / \mathrm{sec}$, the eyes responded at $28^{\circ} / \mathrm{sec}$ resulting in a slip speed on the retina of $40-28$ or $12 \%$ sec. If these retinal units are involved in setting the pursuit response, then it would be predicted that saturation, as evidenced by a decrease in gain, would occur for slip speeds greater than $12 \%$ sec. Unfortunately, the maximum velocity of the drum did not allow testing of this prediction, but the fact that saturation had not occurred at $40 \% \mathrm{sec}$ does weakly support the hypothesis.

In summary, there is much to suggest that the velocity of the smooth pursuit movements in goldfish are controlled by the massed activity of the retinal directionally selective movement sensitive ganglion cells. OYSTER and BARLOW (1967) have suggested a similar scheme for the rabbit.

\section{SUMMARY}

(1) Horizontal rotatory eye movements made by restrained goldfish in response to moving targets have been measured objectively. The target was either a striped drum rotating about the vertical axis concentric with the animal's head or striped tangent screens on either side.

(2) Rotation of the drum evoked saccades in the opposite sense, slow (pursuit) movements in the same sense (optokinetic nystagmus). Movement of the tangent screens evoked appropriately directed pursuit movements in both eyes if both screens moved anteriorly, but no response if both moved posteriorly.

(3) Pursuit velocity varied linearly with the drum for speeds up to $40 \% \mathrm{sec}$, the highest tested. The velocity gain (pursuit velocity/drum velocity) was typically about 0.7 , but was seldom the same for both eyes. Generally the eye moving narad was the faster.

(4) Movement sensed by either eye caused both to pursue, but the response by one was greatest when both viewed, intermediate when it viewed alone, and least when only the contralateral eye viewed.

(5) The size and contrast of the target and the state of adaptation of the animal also influenced pursuit over wide ranges.

(6) It is concluded that pursuit velocity is set by a spatial integration of retinal image velocity sensed over a large part of both retinas, and weighted by the visibility of the pattern.

(7) It is argued that directionally-selective movement-sensitive retinal ganglion cells are probably involved in this process. 
Acknowledgements-Much of this work was done in Professor H. B. BARLow's laboratory in Berkeley. while I held a fellowship from the Miller Institute. I thank the Institute for having supported me and Professor BARLOW for having supported the research through his P.H.S. grant EY-00276. The work in Ann Arbor was supported by P.H.S. EY-00168. I thank Professor G. Westheimer, Professor M. ALPERN and Mr. R. KNighron for many useful discussions, and Mr. M. H. ReHMUs for technical help.

\section{REFERENCES}

ARUENS-Kappers, C. U., HuBer, G. C. and CROBBY, E. C. (1967). The comparative anatomy of the nervous system of vertebrates, including man, Vol. III, Hafner, New York.

Cronty-Dinlon, J. R. (1964). Units sensitive to direction of movement in the goldfish optic tectum. Nature Lond. 203, 214-215.

Cronly-Dulon, J. R. and MunTz, W. R. A. (1965). The spectral sensitivity of the goldfish and the clawed toad tadpole under photopic conditions. J. exp. Biol. 42, 481-493.

EAsTER, S. S. (1971). Spontaneous eye movements in restrained goldfish. Vision Res. 11, 333-342.

GRUNDFEsT, H. (1931). The sensibility of the sunfish, Lepomis, to monochromatic radiation of low intensities. J. gen. Physiol. 15, 307-328.

HARDEN-JONEs, F. R. (1963). The reaction of fish to moving backgrounds. J. exp. Biol. 40, 437-446.

Hester, F. J. (1968). Visual contrast thresholds of the goldfish (Carassius auratus). Vision Res. 8, 1315-1337.

HorRmGE, G. A. (1966). Study of a system, as illustrated by the optokinetic response. In S.E.B. Symposium 20, Nervous and hormonal mechanisms of integration, 179-197.

LYoN, E. P. (1904). On rheotropism. 1. Rheotropism in fishes. Am. J. Physiol. 12, 149-161.

OYSTER, C. W. and BARLOW, H. B. (1967). Direction-selective units in rabbit retina: distribution of preferred directions. Science, $N . Y .155,841-842$.

SchwassmanN, H. and KrUGer, L. (1965). Organization of the visual projection upon the optic tectum of some fresh water fish. J. comp. Neurol. 124, 113-126.

Sperry, R. W. (1948). Patterning of central synapses in regeneration of the optic nerve in teleosts. Physiol. Zool. 21, 351-361.

TAUBER, E. S. and ATKIN, A. (1968). Optomotor responses to monocular stimulation: relation to visual system organization. Science, N.Y. 160, 1365-1367.

Ter BraAk, J. W. G. (1936). Untersuchungen uber optokinetischen Nystagmus. Archs neerl. Physiol. 21, 309-376.

TreVARTHEN, C. (1968). Vision in fish: the origins of the visual frame for action in vertebrates. In The Central Nervous System and Fish Behavior (edited by INGLE, D.), pp. 61-94. University of Chicago Press, Chicago.

WALLS, G. L. (1962). The evolutionary history of eye movements. Vision Res. 2, 69-80.

WARTzOK, D. (1971). Directionally selective visual units recorded in the optic tectum of the goldfish. Ph.D. Thesis, The Johns Hopkins University, Baltimore, Maryland.

Westrenmer, G. (1954). Mechanism of saccadic eye movements. A.M.A. Arch. Ophth. 52, 710-724.

WIEGMANN, O. (1958). Unpublished dissertation. Cited by ALPERN, M. (1969). In The Eye (edited by DAvson H.), Vol. 3, p. 86. Academic Press, New York.

Abstract-Pursuit eye movements made by goldfish were investigated with an optical technique in which the horizontal orientations of both eyes were measured automatically. Moving targets were provided by: (1) a striped drum which rotated about the vertical axis concentrically with the animal's head, and (2) tangent screens on either side. Movement seen by either eye alone caused both to move, but the response was greater when both viewed the drum. The angular velocities of the eyes were always less than that of the drum. The ocular velocity depended upon the velocity, area, and contrast of the target, over wide ranges, and upon the state of adaptation and the recent history of the visual system. Evidence is offered supporting the hypothesis that the pursuit movements are controlled by directionally-selective movementsensitive retinal ganglion cells.

Résumó-On étudie les mouvements de poursuite des yeux du cyprin doré au moyen d'une technique optique qui mesure automatiquement les orientations horizontales des deux yeux. On utilise les cibles mobiles suivantes: (1) un tambour rayé qui tourne autour d'un axe vertival concentrique avec la tête de l'animal, et (2) des écrans tangents de chaque côté. Le mouvement vu par un seul oeil produit un mouvement des deux, mais la réponse est plus grande quand les deux yeux voient le tambour. Les vitesses angulaires des yeux sont toujours moindres que celle du tambour. La vitesse oculaire dépend dans une large mesure de la vitesse, de la surface et du contraste de la cible, ainsi que de l'tetat d'adaptation et de l'histoiro récente du système visuel. On présente les arguments en faveur de l'hypothèse que les mouvements de poursuite 
sont controbles par des cellules ganglionnaires de la rétine, sensibles au mouvement et à sa direction.

Zummmenfing Such-Augenbewegungen des Goldfieches werden mit einem optischen Aufbeu untersucht, bei dem die horizontale Ausrichtung beider Augen automatisch gemessen wurde. Bewegte Testzeichen werden erzeugt durch:

(1) eine gestreifte Trommel, die um eine vertikale Achse konzentrisch zum Kopf des Tieres rotierte,

(2) Berührende Schirme auf jeder Seite.

Auch wean gur ein Ause eine Beweeung sah, folsten beide Aupen, doch war die Reirantwort gröBer, wenn beide Augen die Trommel sahen. Die Winkelecechwindigkeit der Augen war dabei immer geringer abs die der Trommel. Die Augearachwindintkeit hins von der Geachwindigkeit, der Flache und dem Kontrast des Testreichens ober einen groBea Bereich ab, sowie vom Adaptationerustand und der Vorreachichte des vivuellen Systems. Beweine werden angefuhrt, wonach die Suchbewegungen vom richtungaselektiven, bewegungompeindlichen Ganglienzellen der Retina kontrolliert werden.

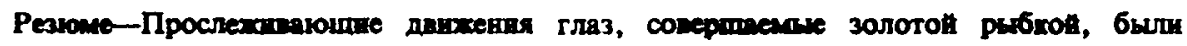

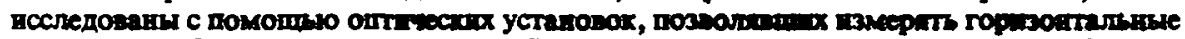

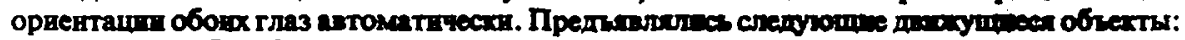

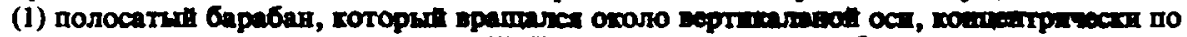

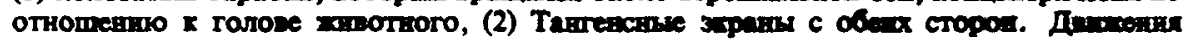

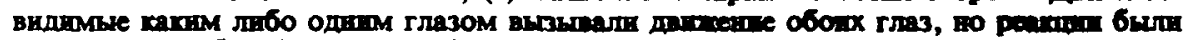

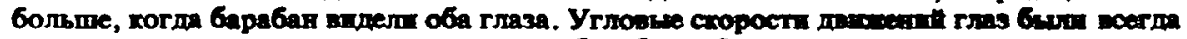

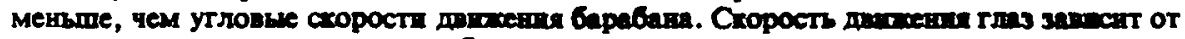

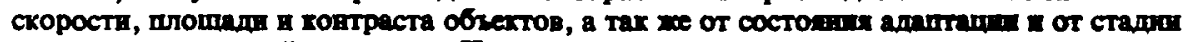

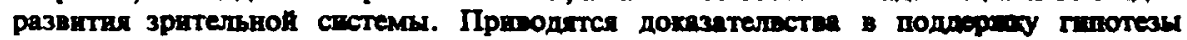

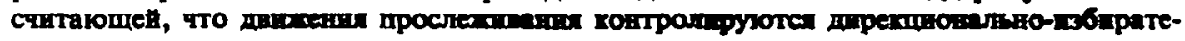

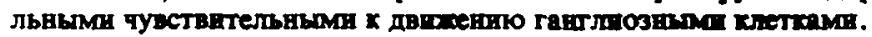

